\title{
Optimasi Model Artificial Neural Network Untuk Klasifikasi Paket Jaringan
}

\author{
Indra Gunawan ${ }^{\mathrm{a}}$ \\ ${ }^{a}$ Sekolah Tinggi Teknologi Ronggolawe Cepu
}

\begin{abstract}
The classification of internet networks is widely used by various parties for saving, allocating, limiting, and administration of internet resources. Various techniques are used, one of which is a machine learning approach, especially an artificial neural network algorithm, hereinafter abbreviated as ANN. ANN works by imitating the way the nerves of the human brain work. ANN in this study is used to classify network packets. The dataset used consists of 990558 rows of data, 4 input columns (X) including protocol, port, time before previous packet, packet length. Output column (Y) consisting of 5 labels (App, Social Media, Game, Browsing, Streaming). Furthermore, this dataset is divided into 3 datasets namely training, test, and validation. The purpose of this study is, first, to determine the ability of the ANN algorithm for classifying packets on a per-packet basis. Second, find the most optimal ANN model for the above problem. The conclusion obtained is that the neural network algorithm can be used in the classification of network packets, but if the dataset used has characteristics such as the number of variables $\mathrm{X}$ is small, the data on the variable $\mathrm{X}$ is very wide distances such as (port, packet size, time to previous packet, protocol) then high accuracy is very difficult to obtain. Second, if the problem solved has similarities with this study, the most optimal ANN model architecture is: one input layer, one hidden layer, one output layer. The number of input layer neurons is 7 times the number of variables $\mathrm{X}$, The number of hidden layer neuron is $1 / 2.8$ times the number of input neurons, dropout value is 0.33 , tanh-tanhsoftmax activation method, adamax optimization method. Stable accuracy values are obtained at the 600th iteration (epoch), stable loss values are obtained at the 1000th epoch.
\end{abstract}

Keywords : Machine learning, artificial neural networks, network packet classifications, internet classifications.

\section{Pendahuluan}

Klasifikasi jaringan internet dibutuhkan secara luas oleh berbagai pihak untuk penghematan, pengalokasian, pembatasan sumber daya internet. Berbagai teknik digunakan untuk hal tersebut, salah satunya adalah dengan pendekatan machine learning khususnya algoritma jaringan syaraf tiruan (artificial neural network) yang selanjutnya disingkat ANN. ANN bekerja dengan cara meniru cara kerja syaraf otak manusia dan sel-sel neuronnya. ANN digunakan pada penelitian ini karena memiliki kelebihan dibanding algoritma machine learning lainnya yaitu dapat memecahkan permasalahan yang komplek yang ditandai dengan variabel yang berjumlah banyak, data berjumlah besar dan bersifat non linier (Michael et al, 2016).

Pengklasifikasian paket jaringan digunakan untuk mengelompokkan jaringan berdasarkan aktifitasnya, misalnya browsing, streaming, chat, game, P2P dan lainnya. Data klasifikasi jaringan tersebut dapat digunakan oleh operator jaringan maupun network administrator untuk optimalisasi bandwith yang digunakan maupun keperluan lainnya. Secara umum pengklasifikasian paket jaringan dilakukan dengan cara menggabungkan beberapa frame paket berdasar sesi nya mulai dari frame pertama sampai selesai satu sesi, kemudian dilakukan proses manual penghitungan besar ukuran paket, waktu awal sampai selesai dan lainnya. Semakin sedikit jumlah framenya maka semakin sulit untuk mendapatkan klasifikasi yang akurat.
Permasalahan utama dalam pengklasifikasian paket jaringan adalah bagaimana mendapatkan keakuratan sekaligus kecepatan prosesnya sehingga tidak memperlambat lalu linntas jaringan, semakin banyak frame yang dibutuhkan dan semakin banyak variabel input(X) maupun outputnya(Y) maka semakin memperlambat prosesnya, demikian pula sebaliknya semakin sedikit frame dan semakin sedikit variabel $\mathrm{X}$ dan $\mathrm{Y}$ akan mengurangi keakuratannya tetapi menambah kecepatan prosesnya. Penelitian ini hanya menggunakan satu frame, sedikit variabel X maupun Y untuk mengetahui apakah algoritma ANN dapat digunakan pada permasalahan tersebut, tujuan lainnya adalah untuk mengetahui model ANN yang paling optimal untuk digunakan.

Machine Learning merupakan cabang dari rumpun ilmu kecerdasan buatan (artificial intelligence). Secara umum machine learning dapat digunakan untuk menyelesaikan permasalahan klasifikasi, kluster, asosiasi, prediksi dan optimasi jalur. Masing-masing permasalahan tersebut dapat diselesaikan dengan berbagai algoritma yang berbeda-beda. Klasifikasi dapat diselesaikan dengan algoritma Logistic Regression, K-Nearest Neighbors(K-NN), Support Vector Machine (SVM), Kernel SVM, Naïve Bayes, Decision Tree dan Random Forest. Permasalahan kluster dapat digunakan algoritma K-Means, Hierarchical Clustering. Asosiasi dapat digunakan algoritma Apriori dan Eclat. Prediksi dengan angka dapat diselesaikan dengan algoritma Simple Linear, Multiple Linear, Polynomial, Support Vector Machine, Decision Tree, Random Forest. Sedangkan permasalahan 
yang lebih komplek seperti robotika, mobil pintar, pengenalan suara, klasifikasi jaringan dan lainnya dapat digunakan algoritma Machine Learning yang lebih khusus seperti Artificial Neural Network(ANN) dan Convolutional Neural Network(CNN) maupun Deep Learning.

\section{Kerangka Teori}

Telah ada beberapa penelitian sebelumnya tentang ANN untuk klasifikasi paket jaringan yaitu penelitian yang dilakukan oleh (Michael et al, 2016), (Liang et al, 2019), (Lopez-Martin et al, 2017), (Lloret, 2017), (Wang, 2017), (Iqbal et al, 2019). Penelitian (Michael et al, 2016) membahas tentang klasifikasi paket jaringan menggunakan ANN menggunakan 10 kelas input dan 1 kelas output, klasifikasi paket-paketnya berdasarkan 1 transaksi/sesi. Penelitian (Liang et al, 2019) meneliti tentang penggunaan Deep Reinforcement Learning untuk klasifikasi paket jaringan pendekatan feature learning. Penelitian (LopezMartin et al, 2017) membahas tentang penggunaan teknik Convolutional dan Recurrent Neural Network untuk peralatan Internet of Thing(IOT). Penelitian (Lloret, 2017) meneliti tentang penggunaan Deep Learning untuk klasifikasi paket. Penelitian (Wang, 2017) membahas tentang penggunaan performa ANN untuk klasifikasi paket jaringan. Penelurusan pada google scholar tentang topik ini membawa kepada simpulan bahwa klasifikasi paket jaringan berdasarkan per satu frame saja menggunakan ANN adalah ruang kajian yang masih perlu untuk diteliti.

\section{Metodologi}

Pengumpulan data dilakukan dengan cara melakukan penyadapan/tapping terhadap jaringan kampus Universitas Ibnu Sina Batam selama lebih kurang total 15 menit, proses ini dilakukan dengan mengambil beberapa sampel selama beberapa hari pada jam puncak keramaian. Setelah mendapatkan beberapa sampel paket jaringan, dataset digabung menggunakan aplikasi wireshark dan diexport kedalam format CSV untuk diproses pada tahap berikutnya. Selanjutnya dibuat kolom 'Klasifikasi' pada dataset CSV, pengisian label pada kolom klasifikasi ini dilakukan secara manual dengan melihat berbagai informasi pada kolom lainnya secara akurat. Labelnya akan diisi dengan string "App", "Game", "Browsing", 'Streaming" dan "Sosmed". Setelah kolom klasifikasi terisi secara penuh, dilakukan penyaringan data dengan menghapus paket "noise". Paket noise adalah paket-paket yang tidak berhubungan dengan lima label diatas, paket ini akan dihapus. Selanjutnya dilakukan penghapusan kolom-kolom dan menyisakan 5 kolom yaitu: protocol, port, timestamp, length dan klasifikasi.

Selanjutnya dilakukan sejumlah perubahan dan pembersihan data pada dataset. Perubahan-perubahan yang dilakukan yaitu: 1. Data hanya diambil dari 4 label yang paling sering muncul dari masing-masing kolom input. 2. Dibuat label 'OTHER' pada masing-masing kolom untuk menampung sisa data diluar empat besar. 3.Dilakukan penyeimbangan data menggunakan teknik over sampling SMOTE yang bertujuan untuk untuk menambahkan data sintetis, kemudian dilakukan pengurangan data dengan teknik under sampling NEARMISS hingga terjadi keseimbangan persebaran setiap label. Label output(Y) dapat dilihat pada tabel 1 berikut ini..

Tabel 1 Daftar Label Input(Y)

\begin{tabular}{lll}
\hline No & Nama Kolom & Jenis \\
\hline 1 & Protocol & Input $(\mathrm{X})$ \\
2 & Length & Input $(\mathrm{X})$ \\
3 & Timestamp & Input $(\mathrm{X})$ \\
4 & Port & Input $(\mathrm{X})$ \\
5 & Klasifikasi & Output(Y)
\end{tabular}

\section{Hasil dan Pembahasan}

\subsection{Optimasi Model}

ANN adalah termasuk algoritma pada Machine Learning yang bersifat supervised, artinya algoritma ini membutuhkan masukan sejumlah parameter untuk dapat menghasilkan keluaran yang maksimal. Tujuan utama penelitian tentang ANN adalah untuk menemukan model yang ideal dan optimal pada kasus yang diteliti. Proses optimasi model dilakukan dengan cara trial dan eror dengan mengubah-ubah sejumlah parameter pada model. Parameter-parameter tersebut adalah: 1. Jumlah neuron pada input layer. 2. Jumlah hidden layer. 3. Jumlah neuron pada hidden layer. 4. Metode aktivasi. 5. Metode Optimasi. 6. Nilai dropout. 7. Batch_size. 8. Iterasi/Epoch. Perubahan-perubahan parameter pada sembilan poin diatas dapat menghasilkan keluaran yang berbeda.

Proses percobaan pada setiap parameter dilakukan dengan cara mengubah satu parameter dengan berbagai nilai dan membiarkan parameter lainnya sehingga didapatkan kekonsistenan hasil. Setelah didapatkan keluaran yang optimal pada satu parameter, parameter yang telah optimal tersebut akan diterapkan ketika melakukan percobaan pada parameter lainnya. Begitu selanjutnya sampai semua parameter dalam kondisi optimal.

Secara matematik, model ANN dapat dirumuskan sebagai berikut, lihat pada Gambar 1 .
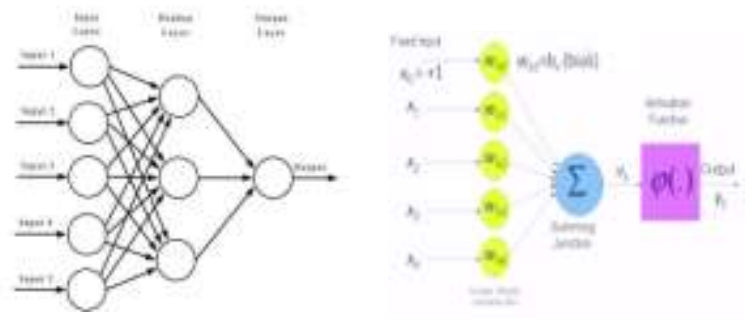

Gambar 1 Model matematik dan model arsitektur layer Artifical Neural Network (ANN).

Neuron pada Input Layer, neuron pada hidden layer, neuron pada output layer serta jumlah layer pada hidden layer dapat dimodifikasi jumlahnya untuk menemukan proporsi yang tepat sesuai masalah yang diselesaikan. Variabel X0 sampai Xn adalah variabel input berisi angka antara 0 dan 1 , pada penelitian ini inputnya adalah protocol, port, length dan timestamp yang dikonversi menjadi angka antara 0 dan 1 dengan menggunakan fungsi persebaran minimum dan maksimum. Variabel $\mathrm{Yk}$ adalah variabel output yaitu kolom klasifikasi. Variabel W adalah bobot nilai pada tiap-tiap variabel $\mathrm{X}$. Setiap bobot yang bernilai 
tinggi akan diambil untuk digunakan pada proses berikutnya sedangkan bobot yang bernilai rendah akan dihapus menggunakan fungsi dropout. Kombinasi dari penghitungan bobot sejumlah variabel input akan terus diperbaiki dari iterasi ke iterasi sampai menghasilkan bobot yang optimal.

\subsection{Input Layer}

Percobaan pada input layer dilakukan dengan cara mengubah-ubah jumlah neuronnya dan membiarkan neuron pada layer lainnya hingga didapatkan nilai loss yang paling kecil. Perubahan nilai pada input layer dapat dilihat pada Tabel 2 berikut.

Tabel 2 Perbandingan Optimasi Input Layer

\begin{tabular}{|c|c|c|c|c|}
\hline \multicolumn{3}{|c|}{ Jumlah Neuron } & Dataset & Loss \\
\hline 28 & 10 & 3 & $\begin{array}{l}\text { Training } \\
\text { Test } \\
\text { Validation }\end{array}$ & $\begin{array}{l}0.3426715 \\
0.3419900 \\
0.3421240\end{array}$ \\
\hline 10 & 10 & 3 & $\begin{array}{l}\text { Training } \\
\text { Test } \\
\text { Validation }\end{array}$ & $\begin{array}{l}0.3646827 \\
0.3639667 \\
0.3639387\end{array}$ \\
\hline 25 & 10 & 3 & $\begin{array}{l}\text { Training } \\
\text { Test } \\
\text { Validation }\end{array}$ & $\begin{array}{l}0.3691933 \\
0.3682538 \\
0.3682329\end{array}$ \\
\hline 3 & 10 & 3 & $\begin{array}{l}\text { Training } \\
\text { Test } \\
\text { Validation }\end{array}$ & $\begin{array}{l}0.3716515 \\
0.3705643 \\
0.3705689\end{array}$ \\
\hline 5 & 10 & 3 & $\begin{array}{l}\text { Training } \\
\text { Test } \\
\text { Validation }\end{array}$ & $\begin{array}{l}0.3760645 \\
0.3755217 \\
0.3754914\end{array}$ \\
\hline 30 & 10 & 3 & $\begin{array}{l}\text { Training } \\
\text { Test } \\
\text { Validation }\end{array}$ & $\begin{array}{l}0.3827678 \\
0.3815309 \\
0.3815142\end{array}$ \\
\hline 70 & 10 & 3 & $\begin{array}{l}\text { Training } \\
\text { Test } \\
\text { Validation }\end{array}$ & $\begin{array}{l}0.3934881 \\
0.3925169 \\
0.3924685\end{array}$ \\
\hline
\end{tabular}

Dari berbagai perubahan nilai yang dilakukan pada input layer seperti terlihat pada Tabel 2 dapat disimpulkan bahwa neuron sebanyak 28 merupakan jumlah yang paling optimal dimana jumlah tersebut dapat menghasilkan nilai loss yang terkecil.

\subsection{Hidden Layer}

Percobaan pada hidden layer terdiri dari dua tahap, percobaan pertama untuk menemukan jumlah layer yang paling optimal, percobaan kedua untuk menemukan jumlah neuron yang paling optimal. Hasil percobaan tersebut dapat dilihat pada Tabel 3 berikut ini.

Tabel 3 Perbandingan Optimasi Jumlah Hidden Layer

\begin{tabular}{lll}
\hline $\begin{array}{l}\text { Jumlah } \\
\text { Hidden } \\
\text { Layer }\end{array}$ & Dataset & Loss \\
\hline 1 & & \\
& Training & 0.3552483 \\
& Test & 0.3537241 \\
2 & Validation & 0.3537502 \\
& Training & 0.3747940 \\
& Test & 0.3735337 \\
3 & Validation & 0.3735103 \\
& Training & 0.4030375 \\
& Test & 0.4020166 \\
& Validation & 0.4019670
\end{tabular}

$\begin{array}{ll}\text { Training } & 0.4060224 \\ \text { Test } & 0.4052239 \\ \text { Validation } & 0.4051619\end{array}$

Dari percobaan perubahan jumlah hidden layer pada Tabel 3, disimpulkan bahwa nilai loss terkecil didapatkan pada jumlah hidden layer satu.

Percobaan pada hidden layer selanjutnya dilakukan terhadap jumlah neuron, di tahap ini dilakukan berbagai perubahan terhadap jumlah neuron dari angka terkecil 3 neuron sampai 14 seperti terlihat pada Tabel 4 berikut ini.

Tabel 4 Perbandingan Optimasi Layer

\begin{tabular}{|c|c|c|c|c|}
\hline \multicolumn{5}{|c|}{ Jumlah Neuron } \\
\hline Input & Hidden & Output & Dataset & Loss \\
\hline 28 & 10 & 3 & $\begin{array}{l}\text { Training } \\
\text { Test } \\
\text { Validation }\end{array}$ & $\begin{array}{l}0.3656147 \\
0.3649282 \\
0.3649409\end{array}$ \\
\hline 28 & 6 & 3 & $\begin{array}{l}\text { Training } \\
\text { Test } \\
\text { Validation }\end{array}$ & $\begin{array}{l}0.3807375 \\
0.3800701 \\
0.3800569\end{array}$ \\
\hline 28 & 14 & 3 & $\begin{array}{l}\text { Training } \\
\text { Test } \\
\text { Validation }\end{array}$ & $\begin{array}{l}0.4174686 \\
0.4164832 \\
0.4164643\end{array}$ \\
\hline 28 & 9 & 3 & $\begin{array}{l}\text { Training } \\
\text { Test } \\
\text { Validation }\end{array}$ & $\begin{array}{l}0.3912370 \\
0.3897505 \\
0.3897160\end{array}$ \\
\hline 28 & 12 & 3 & $\begin{array}{l}\text { Training } \\
\text { Test } \\
\text { Validation }\end{array}$ & $\begin{array}{l}0.4559653 \\
0.4546776 \\
0.4546339\end{array}$ \\
\hline 28 & 3 & 3 & $\begin{array}{l}\text { Training } \\
\text { Test } \\
\text { Validation }\end{array}$ & $\begin{array}{l}0.4589423 \\
0.4579503 \\
0.4579014\end{array}$ \\
\hline
\end{tabular}

Dari berbagai variasi percobaan perubahaan nilai pada jumlah neuron, disimpulkan bahwa jumlah neuron pada hidden layer yang paling optimal adalah 10 neuron yaitu yang dapat menghasilkan nilai loss terkecil.

4.4 Aktivasi

Fungsi aktivasi adalah fungsi matematika yang berada pada hidden layer yang berfungsi untuk mengubah ANN menjadi bersifat non linier. Beberapa fungsi aktivasi yang tersedia pada framework tensorflow adalah: Tanh, softsign, sigmoid, softmax, softplus, linear, relu, elu, exponential. Percobaan dilakukan dengan mengubah fungsi aktivasi dan dihitung nilai loss nya, hasilnya dapat dilihat pada Tabel 5 berikut ini.

Tabel 5 Perbandingan Arsitektur Layer

\begin{tabular}{llllll}
\hline $\begin{array}{c}\text { Layer } \\
\text { Input }\end{array}$ & Hidden & Output & Optimizer & Dataset & Loss \\
& & & & & \\
\hline Tanh & Tanh & Softmax & Adamax & Training & 0.34 \\
& & & & Test & 0.34 \\
& & & & Validation & 0.34 \\
Sotfsign & \multirow{2}{*}{ Sotfsign } & Softmax & Adamax & Training & 0.36 \\
& & & & Test & 0.35 \\
& & & & Validation & 0.35 \\
Sigmoid & \multirow{2}{*}{ Sigmoid } & Softmax & Adamax & Training & 0.39 \\
& & & & Test & 0.39 \\
Softmax & \multirow{2}{*}{ Softmax } & Softmax & Adamax & Training & 0.46 \\
& & & & Test & 0.46 \\
& & & & Validation & 0.46 \\
Linear & \multirow{2}{*}{ Linear } & \multirow{2}{*}{ Softmax } & Adamax & Training & 0.98 \\
& & & & Test & 0.9 \\
& & & & Validation & 0.9
\end{tabular}




\begin{tabular}{llllll} 
Softplus & Softplus & Softmax & Adamax & Training & 0.45 \\
& & & & Test & 0.42 \\
& & & & Validation & 0.42 \\
Elu & \multirow{2}{*}{ Elu } & Softmax & Adamax & Training & 0.77 \\
& & & & Test & 0.74 \\
& & & & Validation & 0.74 \\
\multirow{2}{*}{ Relu } & \multirow{2}{*}{ Relu } & \multirow{2}{*}{ Softmax } & Adamax & Training & 0.99 \\
& & & & Test & 0.91
\end{tabular}

Dari percobaan perubahan fungsi-fungsi aktivasi yang tersedia, dapat disimpulkan bahwa fungsi aktivasi yang paling optimal adalah fungsi Tanh yang menghasilkan nilai loss terkecil.

\subsection{Optimasi}

Optimasi dalam machine learning adalah fungsi matematika yang digunakan untuk memilih nilai yang dianggap paling optimal dari sejumlah nilai pada proses pembelajaran. Percobaan pada tahap ini dilakukan dengan mengubah ubah parameter fungsi optimasi dan menilai hasilnya. Nilai loss yang dihasilkan oleh masing-masing fungsi tersebut dapat dilihat pada Tabel 6 berikut ini.

Tabel 6 Perbandingan Metode Optimasi

\begin{tabular}{ccc}
\hline Optimizer & Dataset & Loss \\
& & \\
\hline Adamax & Training & 0.33 \\
& Test & 0.32 \\
& Validation & 0.32 \\
RMSProp & Training & 0.34 \\
& Test & 0.34 \\
& Validation & 0.34 \\
Adam & Training & 0.35 \\
& Test & 0.35 \\
& Validation & 0.35 \\
SGD & Training & 0.49 \\
& Test & 0.49 \\
& Validation & 0.49 \\
Adagrad & Training & 0.49 \\
& Test & 0.49 \\
& Validation & 0.49 \\
Adadelta & Training & 0.7 \\
& Test & 0.67 \\
& Validation & 0.67
\end{tabular}

Dari berbagai percobaan yang dilakukan, dapat disimpulkan bahwa fungsi adamax menghasilkan nilai loss yang paling minimal.

\subsection{Pengeluaran(Dropout)}

Dropout merupakan fungsi matematika yang digunakan untuk menentukan prosentasi pembuangan nilai yang dianggap paling buruk dari sejumlah nilai yang dihasilkan pada satu tahap pembelajaran. Tujuan dari pembuangan ini untuk mengurangi overfitting pada model, yaitu kondisi dimana nilai akurasi yang dihasilkan terlalu sempurna, misalnya bernilai 1 . Percobaan pada tahap ini dilakukan dengan mengubah-ubah parameter nilai dropout hingga diapatkan nilai loss terkecil. Hasil percobaan tersebut dapat dilihat pada Tabel 7 berikut.

Tabel 7 Perbandingan Nilai Dropout

\begin{tabular}{lll}
\hline Nilai Dropout & Dataset & Loss \\
\hline 0,33 & Training & 0.35 \\
& Test & 0.35 \\
& Validation & 0.35 \\
0,4 & Training & 0.36 \\
& Test & 0.36 \\
& Validation & 0.36
\end{tabular}

\begin{tabular}{lll}
\hline Nilai Dropout & Dataset & Loss \\
& & \\
\hline 0,2 & Training & 0.36 \\
& Test & 0.36 \\
& Validation & 0.36 \\
0,055 & Training & 0.37 \\
& Test & 0.37 \\
0,1 & Validation & 0.37 \\
& Training & 0.42 \\
& Test & 0.42 \\
& Validation & 0.42
\end{tabular}

Dari berbagai percobaan yang dilakukan terhadap parameter dropout, dapat disimpulkan bahwa nilai dropout yang paling optimal adalah 0,33 dimana pada kondisi ini dihasilkan nilai loss terkecil.

\subsection{Optimasi Variabel Input $(X)$}

Pada tahap ini dilakukan percobaan menggunakan 1 sampai 4 kolom input(X) untuk melihat performa loss nya sehingga dapat digunakan untuk menentukan jumlah kolom yang optimal. Perbedaan hasil jumlah kolom variabel input (X) dapat dilihat pada Tabel 8 berikut ini.

Tabel 8 Perbandingan Hasil Pembelajaran Berdasarkan Jumlah Variabel Input(X).

\begin{tabular}{clc}
\hline Jumlah & Dataset & Loss \\
\hline Variabel X & Training & 0.38 \\
& Test & 0.38 \\
& Validation & 0.38 \\
3 & Training & 0.44 \\
& Test & 0.44 \\
& Validation & 0.44 \\
2 & Training & 0.44 \\
& Test & 0.44 \\
& Validation & 0.44 \\
1 & Training & 0.44 \\
& Test & 0.44 \\
& Validation & 0.44
\end{tabular}

Dari percobaan yang dilakukan terhadap jumlah variabel input seperti pada Tabel 8, didapatkan kesimpulan bahwa semakin banyak kolom pada variabel input akan memberikan hasil yang lebih baik. Tetapi untuk mengetahui jumlah kolom maksimal diperlukan penelitian lanjutan.

Nilai accuracy dan loss yang didapatkan dari percobaan variasi jumlah kolom tersebut dapat dilihat pada Gambar 2 dibawah ini.
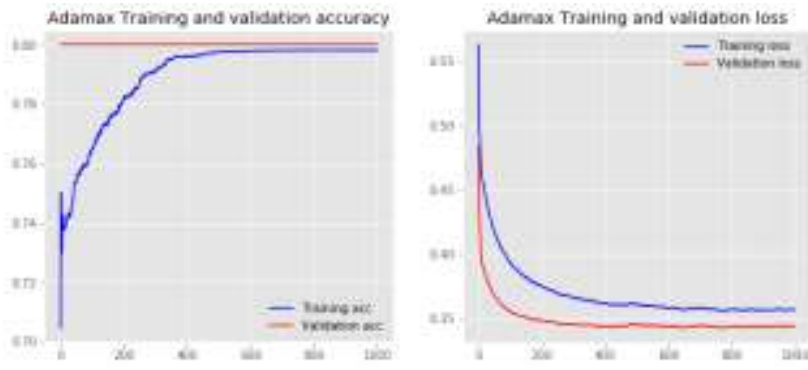

Gambar 2: Diagram Hasil Pembelajaran 4 Kolom $\operatorname{Input}(\mathrm{X})$.

Gambar 2 diatas menjelaskan bawah penggunaan 4 kolom menunjukkan hasil yang accuracy dan loss yang mendekati nilai validasinya. 


\section{Kesimpulan}

Kesimpulan yang didapatkan dari penelitian ini adalah. Pertama, Algoritma neural network dapat digunakan pada klasifikasi paket jaringan, tetapi jika dataset yang digunakan memiliki karakteristik-karakteristik jumlah variabel X kecil, data pada variabel $\mathrm{X}$ sangat lebar jaraknya seperti (port, packet size, time to previous packet, protocol) maka akurasi tinggi sangatlah sulit didapatkan. Kedua, semakin banyak kolom pada variabel input (X) akan memberikan hasil yang lebih baik. Ketiga, jika permasalahan yang dihadapi memiliki kemiripan dengan penelitian ini yaitu pengklasifikasian per satu packet jaringan, maka arsitektur model ANN yang paling optimal adalah: jumlah neuron input layer adalah 7 kali jumlah variabel $X$, jumlah neuron hidden layer adalah 1/2,8 kali jumlah neuron input, jumlah hidden layer satu, nilai dropout 0,33 , metode aktivasi tanhtanh-softmax, metode optimasi adamax, fungsi loss catagory entropy. Nilai accuracy stabil didapatkan pada iterasi (epoch) ke-600, nilai loss stabil didapatkan pada epoch ke1000, sehingga didapat kesimpulan bahwa dibutuhkan iterasi minimal seribu kali untuk mendapatkan hasil optimal.

Penelitian ini memiliki keterbatasan sumberdaya waktu dan peralatan sehingga dapat dilanjutkan penelitian lanjutan menggunakan iterasi sampai sepuluh ribu kali dan nilai batch_size kecil-kecilnya untuk mendapatkan akurasi yang maksimal dan loss yang minimal. Selain itu, dapat ditambahkan variabel $\mathrm{X}$ dengan pembatasan label perkolom maksimal sepuluh label, sehingga algoritma neural network dapat bekerja secara optimal. Untuk melakukan hal tersebut dapat dilakukan dengan menggunakan spesifikasi komputer yang lebih tinggi dan waktu yang lebih lama.

\section{Daftar Pustaka}

A. K. J. Michael, E. Valla, N. S. Neggatu, and A. W. Moore, "Network traffic classification via neural networks," p. 25.

E. Liang, H. Zhu, X. Jin, and I. Stoica, "Neural Packet Classification," ArXiv190210319 Cs, Feb. 2019.

M. Lopez-Martin, B. Carro, A. Sanchez-Esguevillas, and J. Lloret, "Network Traffic Classifier With Convolutional and Recurrent Neural Networks for Internet of Things," IEEE Access, vol. 5, pp. 1804218050, 2017, doi: 10.1109/ACCESS.2017.2747560.

Z. Wang, "The Applications of Deep Learning on Traffic Identification," p. 10.

M. F. Iqbal, M. Zahid, D. Habib, and L. K. John, "Efficient Prediction of Network Traffic for Real-Time Applications," J. Comput. Netw. Commun., vol. 2019, pp. 1-11, Feb. 2019, doi: 10.1155/2019/4067135. 